\title{
Tensions Between the Old and the New: the Influence of Educational Ideologies on Language Learning
}

\section{Introduction}

At the start of this study, in the late 1990's, language teaching at university seemed to be flourishing. Bailey stated in 1994 (p. 41) that language teaching at our universities is thriving because of the mushrooming of language courses at universities, mainly as an extra module available to students of different degree subjects at Language Centres and Institution Wide Language Programmes, and because of the increasing number of modern foreign language degrees where the curriculum displays a greater emphasis on language learning at the expense of literature.

Now, more than a decade later, the situation is very different. Instead, language learning is said to be in crisis. There has been a decline in recent years in the number of student applications for modern languages degree courses except for school leavers from non-state schools. The concern over these falling figures, together with concerns over the funding provision for Modern Languages prompted the Higher Education Funding Council for England to commission a review of language in Higher Education in 2009 to investigate the health of modern languages (Worton, 2009). Worton attributes the decline of students studying modern foreign languages in part to the government's decision to make languages optional for pupils after the age of fourteen (Worton, 2009: 2). But, there are other reasons. Phipps explains the preference for non-language degrees by the fact that students are exposed to a utilitarian 
framework that makes a direct link between their decisions about education and the shape of the labour market (2007: 4). Despite marketing attempts by universities and other stakeholders to convince potential students of the pragmatic value of studying modern languages, students are still 'voting with their feet', she says. In fact, it may be precisely the emphasis on gaining instrumental skills, which is counter-productive when it comes to considerations of employability. Canning (2009: 1, 2) argues that if university language departments keep on marketing themselves mainly in terms of providing the learner with language skills, employers will offer jobs to native speakers whose skills in that language are supreme, and in addition will have other skills than just linguistic ones. Canning makes a distinction between promoting languages as 'skill' and languages as 'discipline', the latter giving learners 'humanities type skills'. $\mathrm{He}$ further cites Brumfit's (2005) rationale for a modern languages degree as 'giving learners the linguistic tools to behave as critical beings in 'other' cultures. For this intercultural understanding linguistic skills are not sufficient, but language graduates 'should possess in-depth cultural insights' (ibid. p.8). Phipps (2007: 35 ) also argues that the field of foreign languages has made a mistake in seeing languages in purely functionalist and employability terms rather than to embrace the insights of anthropological approaches to culture.

I add here my own voice of critique to the instrumental paradigm, and argue that both the humanities with its philosophical underpinning and focus on texts, as well as embracing anthropological insights to culture, can contribute to a language learning pedagogy for engaging as critical beings with 'other' cultures. Whilst I am not aiming to analyse the 'languages in crisis' situation, I do suggest that one of the problems with language study at university is located in the lack of status the subject has had and still has at university. I will turn to this below.

\section{The Position of Language Teaching at University}

When I started this study there was a large variety of pedagogies in language teaching provision in British universities, ranging from the traditional literarybased modern languages degree, modern languages degrees with an emphasis on Area Studies and non-linguistic degrees with language as an extra module, the latter usually provided through a Language Centre. Language teaching as part of a modern languages degree, whether provided by the departments themselves or by a Language Centre, took place as a separate educational activity with a different set of aims from the rest of the degree and carrying much less prestige. This lack of prestige was borne out particularly by staffing levels, terms of employment and hours allocated to language teaching within the curriculum as a whole. In 1992 Scott et. al. pointed already to the fact that the majority of language teachers were part-time and hourly-paid, and on temporary contracts. This situation does not seem to have changed. Teachers in Lan- 
guage Centres are still frequently on vulnerable contracts (Worton, 2009: 31). Whilst, in comparison with a decade ago, there is a tendency in departments to employ specialised language teachers, they are not part of the 'academic staff', and as Worton says (p.26), are seen to provide 'service teaching. Moreover, in many departments the tradition still persists of (junior) lecturers with specialisms other than language and no specific qualification or experience in language teaching, teaching language classes in order to fulfil their share in the teaching load of the department. This illustrates the view that is still common at some institutions that language teaching can be carried out by any intelligent native speaker with some sensitivity towards the language. When this is seen against the situation for other subjects, the likelihood of appointing nonspecialist staff to teach for instance a literature class, would be an extremely unlikely occurrence.

Whereas the curriculum for modern language degrees as a whole is changing - with the traditional literary degrees (although they still exist) giving way to contemporary cultural studies, including contemporary literature, film studies and Area Studies (Worton, 2009: 25), language teaching still remains separated from the rest of the degree in status and content. This separation is even starker now that instrumental approaches have been adopted.

\section{Classical Liberalism Versus Instrumentalism}

Until the shake-up of the Higher Education system in Britain, which started in the sixties with the expansion of Higher Education and which culminated in the early 1990s in the transformation of the former polytechnics into universities, the educational aim at universities had been firmly rooted within a liberal philosophy of education. The key pillars of this philosophy are the pursuit of knowledge and rational autonomy; the development of the individual student towards independence of mind applied within the confines of a body of knowledge established as 'truth' in order to advance the discipline. These classical Enlightenment ideals were emancipatory - both for the individual in his striving for betterment, and for society, although this emancipation served particularly the emerging middle classes in the 19th century where the discourse of rational argument and cultural discourse were developed in the coffee-houses in England as part of an oppositional stance to the absolutism of a hierarchical society (Eagleton, 1984: 9-12).

The traditional liberal paradigm, with its notion of 'promoting the general powers of the mind' (Robbins (1963), quoted by Dearing, 1997: 71), has come under attack from several angles. One of these criticisms relates to the exclusivity of Higher Education towards certain groups in society. This is also an issue of concern addressed by Dearing (1997) in his report. This concern may now seem superfluous, since, the last 20 years or so, the university system has undergone a huge increase in the number of school leavers going to university. Whether this 
mass expansion was due to an instrumentalist neo-liberal response to the need for flexible labour markets or out of a liberal concern with equality is of course debatable. Nevertheless, the traditional Russell Group of universities still admit a proportional higher number of students from middle class backgrounds in comparison to the so called 'teaching universities'. Criticisms have also been directed at the philosophical underpinnings of the traditional liberal humanist paradigm. Its notion of emphasising individuality, rather than seeing individuals as being rooted in society, and its notion of pursuit of 'truth' is one which does not fit in a post-modern era. Jonathan (1995: 75-91) points out that modern liberalism has become free from the social baggage and the emancipatory idiom of its classical origins and argues for an examination of the ontological and ethical questions which are central to the development of consciousness and to the relation between the individual and the social. She points to the theoretical inadequacies of a paradigm which aims to develop maximal individual autonomy of each, for the eventual social benefit of all. The causal connection between these (individual autonomy and a socially better world) remain unexplained within liberalism, Jonathan says, and do not provide a theoretical position to reconcile the 'twin contemporary pulls of illegitimate value imposition and incoherent relativism'. She argues for reconstructing the theory of liberal education within a social theory; reconstructing the concept of autonomy as a socially located value. The key issue which Jonathan points out regarding the apparent conflict of the development of the individual within the social, is one that is also relevant for language teachers. A concern with the individual finds resonance in a new development within language teaching where pedagogies are shifting attention from a fixed authoritative curriculum to a focus on learners' identities and subjectivities (cf. Phipps, 2007; Fenhoulhet and Ros i Solé, 2010 and 2013; Quist, 2013).

As Apple (1990) points out, theories, policies and practices involved in education are inherently political in nature. Changes within the educational system thus rarely, if ever, come only from philosophical considerations, but are politically motivated. This was certainly the case in the 1980s when a huge paradigm shift occurred in education. At many universities education came to be seen in terms of a market philosophy: education as responding to economic needs. Education in the 21st century is now not solely described in terms of the development of the individual and rational autonomy. Instead, the need to fit in with the demands of a fast changing world and the importance of the global economy have started to define curricula. Dearing (1997) emphasised the need to extend the - what he saw as still relevant - liberal aim of 'training the power of the mind' to include the needs of the world at large.

The paradigm shift from a liberal towards an instrumental view of education has been particularly pronounced within language teaching at universities. The rationale for language teaching has therefore changed from a view of increasing knowledge about a culture and developing one's critical and analytical ability, to 
one which is couched in a discourse which emulates such values as the need to regain a competitive edge, overcoming a shortage of skills, not losing business to competitors abroad and so on.

The impact of the instrumental philosophy on language teaching has been phenomenal, but not always in a beneficial way. In the next section I discuss the language teaching approaches at university within these two paradigms and evaluate their contribution to the educational aim of developing critical language users. I will look at their strengths and weaknesses and suggest that the implementation of communicative approaches - in their extreme form - have contributed to the lack of status of language teaching. I discuss the approaches in their most 'pure' form, although naturally one could expect that teachers 'borrow' from either paradigm.

\section{The Liberal Tradition}

Within the liberal tradition the aim of modern language teaching at university level was - and still is - both cultural and intellectual. Bailey (1994: 41) formulates it as instilling an appreciation of foreign literature and language through a scholarly analysis of their content and structure. This is achieved through the study of 'esteemed' canonical literary texts of the past as well as a historical approach to linguistics.

Language teaching itself, within this tradition, has been modelled on the teaching of the 'dead languages', as the classics were seen as the highest expression of the liberal philosophy (Bailey, ibid.). The rationale for teaching language was to contribute to its two important aims of developing the cultural and intellectual capabilities and sensibilities of students. Whereas language learning has never been seen as an important intellectual activity in its own right (outside the subject of philology or linguistics), there was a recognised academic element in the learning of grammar. The cognitive powers of the students were challenged by exercises in sentence parsing and translation of de-contextualised sentences - even if this resulted in artificial language use - in order to apply the rules of logic and show a thorough understanding of the underlying grammatical intricacies. The emphasis was strongly on grammar and the development of written skills - an oral element to language teaching was either non-existent or incidental. This is because communication had no role to play in the traditional liberal humanistic language curriculum; its rationale for language teaching is the teaching of logical thinking skills and an 'objective' way of describing reality. Interestingly, as Cope and Kalantzis (1993:3) point out, this traditional curriculum of prescriptive grammar has mistaken, even deceptive, pretensions to the timelessness of the classics. In ancient Greece and Rome the use of grammar was applied to the social context, forming an integral part of the teaching of dialectic or rhetoric. The classical language curriculum thus 
has a pragmatic communicative origin and a communicative function, which was never followed up on and which diametrically opposes the methodologies based on teaching a 'dead language'.

The second aim which informed the teaching of language was the access it provided to cultural products by exposing the student to 'good' language use and developing an aesthetic appreciation of language, through the study of a canonical body of literary work. This embodied the liberal humanist principle of language as striving for human perfection and beauty based on the Enlightenment ideas about the interpretation of the concept of culture and a wider epistemology. 'Culture' within this tradition encompasses elements of aesthetic and spiritual development (Williams, 1976, 1983: 90) which are enshrined in the valued canonical body of artistic - mainly literary - products of that society. This view pays homage to Matthew Arnold's $(1869,2006: 40)$ definition of culture, and its emancipatory idea of striving for betterment: 'culture is [.....] a study of perfection. It moves by the force, not merely or primarily of the scientific passion for pure knowledge, but also of the moral and social passion of doing good'. In addition, this epistemology contains within it a belief in the rational autonomous subject who can use language to control meaning. Language offers endless opportunities to describe a reality which is located outside language itself. There is a belief in the 'true' and 'real' self and the universality of language. I will discuss this further in chapter 2.

One will not find Arnold's view of culture and its moral good quoted in departmental aims and objectives at universities. Nevertheless, the tradition of literary degrees espouses the core of these values, which were up until recently widely accepted at many universities and still inform departmental courses, although this is more likely to be the case at pre-1992 Russell Group universities. At many of these institutions students studied a canonical body of works to 'sustain a moral criticism of the world' and to recognise the 'little knots of significance' in order to make sense of the world out there and to make 'distinctions of worth' (Inglis, 1992: 220). These liberal values are also reflected in the approach taken in studying canonical works, approached from a strong belief in the authority of the writer, rather than the poststructuralist emphasis on reader interpretation.

It follows that language teaching has a somewhat diminished role within this paradigm as far as language production is concerned. The aim of language teaching is to instill a sense of appreciation for the language and to recognise language as it functions and gives meaning to the 'individual' voice of the author. Language teaching is not geared around developing a language proficiency or communicative ability. Everyday language is of no academic interest. Only literary language and the voice of the author are worthy of study and so literature classes are generally taught in English and the discourse of literary criticism will take place in English rather than through the target language. Language learning and teaching achieve intellectual worth, as mentioned before, only through the study of grammar and translation, supplemented by précis and essay writing. 
The traditional methodology has been heavily criticised and is seen as being thoroughly outdated, precisely because of its lack of placing language in relation to its immediate context or related to wider social and cultural forces which may influence language utterances. Students will have knowledge about the language, but will not be able to speak it. Cook $(1989: 127,128)$ points to the fact that the traditional approach to language learning does not take account of how meaning is created through a unified stretch of text. In short, grammar-translation approaches do not stand up to scrutiny within applied linguistic theories as the sole method of teaching language proficiency. Whilst this approach may be used at university language teaching at some of the traditional institutions, it will indeed not be used in language courses which teach at ab-initio level. Ab initio courses, and indeed increasingly language courses at all levels, generally are influenced by the instrumental paradigm.

\section{The Instrumental Paradigm}

\section{Aims and Practice}

At the other end of the spectrum to the traditional liberal language degrees are language courses which are informed by instrumental values. As with language provision in general, there is a rich variety in the practices in business and pragmatically oriented language classrooms, so any attempt to describe these is by nature doomed to be a gross generalization. Yet, there are certain characteristics which can be recognised as being fairly representative of language classes influenced by instrumental considerations. Because the aim of language classes of this kind is to provide students with the 'real-world' skills which are valuable to employers, language classes are aimed at developing a communicative competence. This would include an emphasis on speaking and interpersonal skills over writing because employers do not necessarily expect graduates to have written competence in the foreign language: “...they want people who can have everyday conversations and state of the art conversations - in other words they know the French for computer or keyboard" (quoted in Scott et. al., 1992: 18). These instrumental approaches, which at the time of starting this study may have been haphazard, have become systematically part of language teaching at universities, since the Common European Framework (CEF, 2001) has been published.

The CEF is a guideline document and does not suggest particular teaching methodologies, but instead provides an extremely detailed taxonomy of the competences, skills and knowledge that learners should possess at certain levels of study. The general aims and principles which are formulated emphasise both the functional aspect of language learning (learning to communicate in order to encourage collaboration, mobility and trade) as well as the moral aspect (respect and understanding for other cultures). However, certainly when 
judged by course books in Dutch which are taking account of the CEF guidelines, the practice has developed on very instrumental lines, concentrating on transactional tasks such as buying train tickets, filling in a form, writing letters or covering conversational interests on an easy interpersonal level such as talking about leisure pursuits and interests or cultural customs.

Clearly the purely instrumental view of language teaching does not fit in well with the liberal ideal of critical thinking; language as an expression of individual thought and emotion. Inglis (1992: 221), for instance, takes a traditional liberal view when he bemoans the loss of a critical and aesthetic and value-based view towards language. He feels that 'to withdraw from the question of value making at the heart of language is $[. .$.$] to hand language over to technicism$ and the skills-mongers whose very function is to demoralise education in the name of its orderly management.'

Within this light it is understandable that with the advent of communicative language teaching (CLT), the discipline came even more to be seen as a nonintellectual subject at the traditional departments. One can legitimately question whether the needs of employers should inform curricula in such a narrow way. Employers are not pedagogues and cannot be expected to know what the best educational route to a final aim of communicative competence is. As well as a reductive skills and information based approach to language learning at the expense of a critical approach to knowledge production, there is another problem with the instrumental approach.

It is absolutely the case that communication skills are of paramount importance to our graduates. They will need to be able to function communicatively in a complex world with many different people, in many different situations, the vast majority of which will be defined by unpredictability, fluidity and changeability. Teaching standard rules and guidelines for these situations, as instrumentalist language teaching does, encourages a labelling of communicative partners into essentialised entities devoid or complex personal histories. But there is also a political point to make. As Fairclough said, in many professional domains, power and manipulation are exercised through language in increasingly subtle and implicit ways (Fairclough, 1992: 3). Teaching set rules for communicative situations could, whether unwittingly or not, contribute to developing skills in students, which perpetuate this exercise in manipulation. I discuss this further in chapter 2, but it is worthwhile to note here that when offering texts from a commercial professional domain to students, the discourses of the legitimacy of self-enrichment and capitalism become naturalised to such an extent that students might employ these uncritically themselves.

Furthermore, the uncritical submitting to employers' needs when drawing up syllabi may train future graduates to fit in with the economic needs of society, but it denies them the development of capabilities aimed at effecting changes in society themselves. As Hoggart (1995: 22) points to the political aspect of instrumentalism; it trains people like robots to serve the needs of industry which is 'one way of avoiding [...] 'looking seriously at injustice which 
runs through the educational system' and 'indicates mistrust [...] of mind and imagination'. Moreover, the focus on market forces is a safe political position: it 'provides a piece of firm dry land for many of today's politicians, barren though that land may be intellectually and imaginatively' (ibid.: 25).

\section{Underlying Theories}

Because of the instrumental aims, the immediate concerns in language classes within this paradigm are practical; developing skills and presenting learners with ready-made phrases or expressions for use in particular situations. The theoretical premises which underlie communicative language teaching (which generally informs instrumental approaches) are therefore often subsumed by practical concerns. Communicative approaches, with an emphasis on real communicative tasks, the use of authentic material in the syllabus and an emphasis on 'getting the message across', are based on pragmatic descriptions of language use derived from Hymes' notion of communicative competence (1972) and Speech Act theory (Austin, 1962).

These approaches generally start from a sociolinguistic description of how meaning is communicated in particular settings, situations and contexts and take account of a variety of parameters such as the intention to mean, the relationship between participants in the communicative act, the topic, the mode of communication and so forth. The view of language which is implicit in communicative syllabuses is thus a pragmatic one; language is seen in a functional goal-oriented sense. This contrasts with the classical liberal view which sees language on the one hand as a creative and aesthetic expression of individual thought and on the other hand as a system of formal rules. Since I started to develop my language course in the mid 1990s, communicative language teaching (CLT) has increasingly been aiming for not only developing Communicative Competence, but also for Intercultural Communicative Competence. However, these original pragmatic concerns remain the bedrock of CLT.

The two approaches I discussed here are thus almost diametrically opposed in their educational aims. The liberal tradition aims to develop autonomous critical thinking and an aesthetic appreciation whereas language learning in the instrumental or communicative approach aims at developing the competence to be able to communicate in work and social environments, including intercultural situations.

It follows then that the pedagogical theories underlying these views also differ, but in the case of the liberal tradition of language teaching, even though based on clear educational values, there is no theory of language learning which informs teaching methodology. As we have seen, the approach was based on the way that the classical languages were taught. In the instrumental approach to language learning, I want to suggest that the problem is reversed. There is no concern with personal or educational development in many instrumentally 
based language classes, as the main concern is to develop skills in the learner which are useful on the job market. The language teaching itself within these classes, on the other hand, is influenced by theories of language learning as an automatic process, which I briefly set out below.

Chomsky's research in mother tongue language acquisition in particular has influenced early communicative approaches in foreign language teaching: as language learning is an automatic process, the argument goes, the role of the teacher is to provide language input of the right level and tasks and situations through which the learners can practise and absorb the use of the foreign language.

Chomsky relates the idea of language acquisition specifically to the grammatical rules. However, in communicative language teaching it has become a common sense notion that the social rules of a language (the appropriateness of utterances in relation to the context in which they are expressed) are acquired along similar lines as these grammatical structures. These social rules constitute what Hymes calls 'communicative competence' (1972).

What is problematic about the view of an automatic acquisition of communicative competence, is that it might explain how certain functional phrases or vocabulary items are acquired, but it allows no role for the wider social and cultural influences which shape communication and discourses. It is possible that these are acquired automatically as well. Children certainly seem to have an uncanny ability to switch their 'social voice', without explicitly having been taught how one speaks within certain social or cultural groups. This ability to 'switch codes' is likely to have been 'picked up' from the various discourses they are exposed to in their environment, notably through television. The question for language teachers, however, is not so much whether language, which is saturated with social or cultural values, can be acquired automatically, but whether it should be.

If we want students to understand how language creates both explicit and implicit cultural and social meanings, then they need not internalise linguistic items automatically. On the contrary, they need to look at language consciously both to understand texts as a social and cultural construct, but also to be enabled to produce language utterances which are culturally and socially appropriate. This is an intellectual skill, which is not automatically achieved in a foreign language and would need to be addressed consciously.

In summary, the instrumental approach to language teaching, which views language particularly in terms of its pragmatic function is much more sophisticated than the liberal tradition in terms of learning to communicate in various settings and in terms of views on language learning. But it is lacking in other ways. Firstly, the emphasis on context as shaping language utterances tends to be interpreted only in terms of the immediate parameters that define a communicative situation and often this is interpreted in fairly reductive terms in the choice of settings, dialogues and texts. This only takes account of the immediate social context, and not the wider cultural influences and the larger social 
constructs, which Halliday (1989), using Malinowski (1923), defined as being of importance in language use. Secondly, while the emphasis is on intention to mean, it assumes that language use is always explicit in its functions and aims, it does not allow for the more implicit social and cultural values which are embedded in texts. I will discuss this further in chapter 2.

\section{A Re-accentuation of Elements of the Liberal Approach}

Whilst the instrumental approach to language teaching may be unsatisfactory in terms of thinking more critically about language use, the failure of the traditional liberal approach to develop communicative competence is also evident. Yet, even if the paradigm offers little towards a theory of learning, and towards creating social meaning, I do not want to dismiss the liberal tradition outright. The actual methodology of grammar and translation is not as reviled as it was during the heyday of communicative language teaching. There is increasingly a general recognition of the importance of explicit grammar teaching. Translation in particular, is also seen as a new area to increase textual and stylistic awareness, particularly from a cultural point of view. It can open up areas of cross-cultural study in examining how language mediates underlying cultural values through, for instance, its use of vocabulary and metaphor (Byram, 1997; Lantolf, 1997). Translation involves cultural negotiation. In addition, activities such as précis writing coupled with the inclusion of 'serious content' contribute to the intellectual development of the student and echoes Cummins' (1979) notion of the need to develop a cognitive academic language proficiency as well as basic interpersonal communicative skills. However, grammar and translation, even though they have a place in the language curriculum, cannot be the sole elements of language teaching.

The notions in the liberal paradigm which are worth exploring in greater depth for their possible potential in language teaching are located in three areas: a) intellectual stimulus and criticality; b) the idea of a language user speaking with an 'individual voice' to express her humanity (cf. Kramsch, 1993); and c) the notion of morality.

These elements combine easily and almost naturally in a language classroom because the content of the classes can be fluid and contain any topic from pragmatic transactions to intellectually challenging discussions on any cultural, social, political or other issue which interest the students. It is precisely the intellectual engagement which is one of the strengths of the liberal paradigm in education, and which has been almost completely lacking in instrumental approaches. This brings us to the second notion of 'expressing individual meaning. It is through content-based discussions that an exchange of complex thought and cooperation can take place and that room can be given to students to express their unique experiences and thoughts. This will contribute to students' intellectual development as they may come to think about issues in a 
different light or come to realisations and ruminations, to experience perhaps the 'life-changing conversations' (Attinasi and Friedrich quoted by Kramsch, ibid. p. 29) taking place through the medium of the foreign language. However, the notion of expressing individual meaning needs to be problematised, which I will do in the next chapter.

The third notion of morality in the classical liberal paradigm can be easily translated to a modern context for language teaching through its emphasis on the emancipatory role of education and its view of a morally and socially better world. At the time that I collected the data for this study, this notion was embedded in the concept of language teaching for 'European citizenship' (Byram, Zarate, Neuner, 1997). This requires, as Byram said, more than mainly pragmatic and functional language teaching, but is rooted in a more comprehensive concept of living together. In terms of language teaching this meant emphasising attitudes of mutual tolerance and a readiness to exchange views. This idea has been developed by, amongst others, Starkey whose pedagogy of political education and human rights awareness through foreign language teaching aims for 'the development of democracy and active citizenship' (Starkey, 1999: 156). Pedagogies taking such an explicit citizenship approach tend to focus on content as knowledge in the language class. Recent developments in this area tend to move away from the original national focus of citizenship education and offer cosmopolitan perspectives (cf. Starkey, 2010), critical perspectives (cf. Guilherme, 2002) and transnational perspectives (cf. Risager, 2007). Whilst I believe the citizenship and knowledge agenda in language pedagogy are very important, I focus in this book largely on a text analytical approach, which, though less knowledge focused, incidentally also assumes a broader cosmopolitan and transnational perspective, as I will set out in greater detail in chapters 3 and 4 . In my own pedagogy, the moral element is less fore-grounded than in citizenship education, although it is present through critical discussions about texts in class, and through the idea of taking responsibility for the reader. The latter, to which I refer as 'addressivity' (cf. Bakhtin, 1996 (1986)) comes into play when students do writing tasks.

Whilst all three elements of the liberal humanist paradigm which I felt warranted re-articulation, are to some extent present in my own pedagogy, it was particularly the intellectual engagement and the critical element which I focused on in the pedagogy on which this book is based. This critical engagement is emphatically not present in the instrumentalist approach. Nevertheless, it was clear to me that the liberal humanist paradigm itself was unable to provide the theoretical framework for language teaching with a critical emphasis. Its notions of objectivity and language as neutral are counter to the idea of encouraging learners to see the complexity of language and culture. My interpretation of intellectual engagement was not so much the idea of providing interesting or challenging articles in the classroom (although that too was important), but my main objective was primarily for students to engage with texts in a critical manner. My aim was for students to become 
critical intercultural language users. Whilst my starting point was the critical perspective taken in the liberal humanist paradigm, I also wanted students to engage with other critical perspectives. This, however, brings with it the problem of incommensurability.

\section{Problematising Intellectual Engagement}

The concept of criticality needs some explanation. I do not refer here to 'criticising' in the sense of disagreeing with or objecting to something, although that could of course be part of it. I am following Pennycook (2001: 5) in describing three different approaches to criticality in relation to applied linguistics. The first approach that Pennycook identifies is what he refers to as critical thinking, associated with the liberal educational paradigm. This is also often referred to as 'taking critical distance' - the term already suggests there is an assumed objectivity in this perspective. This approach develops 'questioning skills' in the learner and involves bringing a 'more rigorous analysis to problem solving or textual understanding' (ibid:3). Critical thinking in this paradigm assumes certain universal 'rules' of thought, which are based on rationality, logic, evidence, precision and clarity. In my context of work, it was this perspective on criticality which was dominant at the time in which this study is set. As I explain further in chapter 4, it also used to be an element in my own teaching practice, in analysing texts partly in relation to argumentation structures, and emphasising cohesion and coherence and generally the need for clarity in students' own writing. It also formed a small part of the course I taught the year I collected the data for this study, and as I describe in relation to the empirical data in chapters 5 and 6 , the incommensurability of these approaches led to a certain confusion amongst students.

The second approach of criticality that Pennycook refers to, is what he calls the modernist emancipatory position. This approach is associated with the neo Marxist tradition and is based on Critical Theory. This approach sees an engagement with political critiques and social relation as the most important aspect of critical work. It aims to work towards social transformation and to tackle social inequality and injustice. In language teaching this approach is taken on by the Critical Language Awareness (CLA) movement (cf. Wallace, 2003; Fairclough, 1992; Fairclough and Wodak, 1996), where texts are analysed for the way they construct ideological positions legitimising domination and social and economic inequality. Whilst my own view was less about unmasking dominant power positions and ideologies, but more about discursive construction in general, I felt the modernist position to be a useful one for its focus on discursive constructions in texts. Also this critical paradigm offered available frameworks for text analysis, notably that of Wallace (2003), from which I borrowed for my own pedagogy. 
The third approach to criticality is generally associated with the 'post' philosophies, such as feminism, poststructuralism and postcolonialism and queer theory. Pennycook refers to it as problematising practice, which consists of 'mapping discourses'. This position is also inherently political as it articulates a scepticism about truth claims made in texts (Pennycook, 2001: 42). In mapping discourses it asks questions about the social, cultural and historical locations of the speaker. It seeks a broader understanding of 'how multiple discourses may be at play at the same time' (Pennycook, 2001: 44). It is this approach to criticality which particularly underpins my own pedagogy, because of its concern with discourses in general, although the other two approaches to criticality, 'critical thinking' and critique of ideological power positions are also present. My aim was for students to be able to deconstruct the text positions and be able to respond to the 'truth claims' in a text rather than reading a text at face value as if it contained an 'existing truth'. This aspect of criticality also allows for culture to be brought into discussions around language, communication and texts as I conceive of discourses as the practice where language and culture are merging. I develop this idea further through the idea of 'cultuurtekst', which I describe in chapter 3.

I did initially conceive of these levels of criticality as pedagogical stepping stones. The first stone of 'critical thinking', I considered as a useful perspective on text to sharpen students' critical ability, to query and question what a text is about and whether its structure, presentation and argumentation will stand up to scrutiny. This, I felt was the first step towards the more sophisticated levels of critique which are embedded within the other two approaches: particularly the third level of critique, which involves the problematising of meaning and texts by acknowledging complexity.

At the time of data collection, I was aware that I applied theoretically incommensurable elements. The 'critical thinking' paradigm assumes a view of objectivity, which clashes with the 'problematising practice' of critique which asks questions, eschews simple straight forward answers and demands self reflection of the learner. Yet, I felt that this incommensurability reflects the complexity of the linguistic, social and cultural world we are introducing the learners to; this is after all fluid, messy and full of contradictions and inconsistencies that students need to deal with in their everyday life.

\section{Conclusion}

In this chapter I have traced the two paradigms which have influenced language teaching at universities in Britain. I have argued that neither of these provides the framework for language teaching that takes account of our complex society and complex needs of learners. Since this study took place, the instrumental paradigm has, as a response to the perceived crisis in language learning, grown still stronger and the liberal language classroom has become the 
'dinosaur' of language learning. Clearly, instrumental aims are important, but even more important is, I feel, the developmental role of education. One of the key elements of the liberal paradigm, which is worth re-articulating, I argued, is that of the intellectual and critical aspect of language learning. However, I have also argued that the notion of criticality adhered to in the liberal paradigm itself with its assumption of objectivity, cannot solely provide the critical skills students need to engage with the complex social and cultural world. This engagement is more likely to be occasioned using a problematising approach of criticality towards texts by 'mapping' discourses; recognising the ways texts construct in culturally routinised ways the world and 'make sense of the reality to which it belongs' (O’Regan, 2006: 118).

Learning a foreign language is not just learning a useful skill; it has the potential to empower the students in enabling them to participate in a critical way in a foreign culture and to understand more about the nature and motives which lie behind communication. In order to address this question, I will look in the next chapter in greater detail at the relationship between language, meaning and culture and how these have impacted on language teaching

Some parts of this chapter were previously published in Quist, G. (2000) Language Teaching at University: A Clash of Cultures, Language and Education (14), 2. 